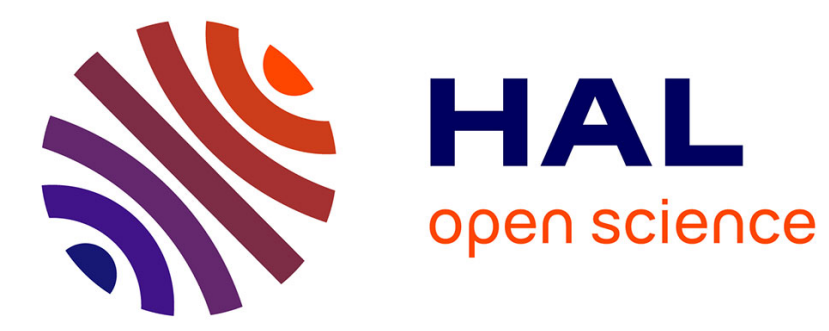

\title{
Apparent Henry's law constants of furan in different n-alkanes and alcohols at temperatures from 293 to 323 K
}

\author{
Martha Hajiw, Alain Valtz, Elise El Ahmar, Christophe Coquelet
}

\section{- To cite this version:}

Martha Hajiw, Alain Valtz, Elise El Ahmar, Christophe Coquelet. Apparent Henry's law constants of furan in different n-alkanes and alcohols at temperatures from 293 to $323 \mathrm{~K}$. Journal of Environmental Chemical Engineering, 2017, 5 (1), pp.1205-1209. 10.1016/j.jece.2017.02.001 • hal-01475872

\section{HAL Id: hal-01475872}

https://hal-mines-paristech.archives-ouvertes.fr/hal-01475872

Submitted on 24 Feb 2017

HAL is a multi-disciplinary open access archive for the deposit and dissemination of scientific research documents, whether they are published or not. The documents may come from teaching and research institutions in France or abroad, or from public or private research centers.
L'archive ouverte pluridisciplinaire HAL, est destinée au dépôt et à la diffusion de documents scientifiques de niveau recherche, publiés ou non, émanant des établissements d'enseignement et de recherche français ou étrangers, des laboratoires publics ou privés. 


\title{
APPARENT HENRY'S LAW CONSTANTS OF FURAN IN DIFFERENT N-ALKANES AND ALCOHOLS AT TEMPERATURES FROM 293 TO $323 \mathrm{~K}$
}

\author{
Martha Hajiw, Alain Valtz, Elise El Ahmar, Christophe Coquelet* \\ Mines ParisTech, PSL Research University, CTP - Centre of Thermodynamics of Processes, 35 rue \\ Saint Honoré, 77305 Fontainebleau Cedex, France
}

\begin{abstract}
Green chemical compounds with high added value can be obtained after pyrolysis of lignocellulosic biomass. This biomass is playing a major role in the chemical sectors as a substitution material. This study is focused on one of these compounds, furan. High selectivity of a solvent is the most important criteria for an optimised extraction. In other words, for the selected solvent, activity coefficients of the compounds to be separated must be different. Therefore, experimental activity coefficients of compounds of interest in different solvents are necessary. In this paper, apparent Henry's law constants of furan in different $n$ alkane and alcohol solvents have been measured at temperatures from 293 to $323 \mathrm{~K}$ using the inert gas stripping method to analyse their potential for furan extraction. Besides, if the value of limiting activity coefficient is close to one, it is an indicator of its suitability for the compound extraction.
\end{abstract}

Keywords: furan, alkane solvent, alcohol solvent, apparent Henry's law constant

\footnotetext{
* Corresponding author:

E-mail: christophe.coquelet@mines-paristech.fr

Telephone: +33 (0) 164694962 .
} 


\section{INTRODUCTION}

With the growing population and the economical development of non-OECD nations (ie. outside the Organization for Economic Cooperation and Development), the world energy consumption is expected to increase by $48 \%$ until 2040 [1]. To fulfil the demand, mankind is facing various challenges: depletion of easily accessible oil fields, exploitation of deepwater or unconventional fields, carbon dioxide emissions. Therefore, part of research is now dedicated to the development of high value compounds. The most promising raw material is lignocellulose, which is, according to Lange et al. (2012) [2], cheaper, more abundant and sustainable. It comes from plant biomass (wood residues, cereal straw and forestry waste), which is made up of lignin and cellulose [3]. After pyrolysis of lignocellulose, a pyroligneous liquid is obtained, containing numerous oxygenated molecules such as aromatics, esters, phenols.... The thermodynamic behaviour of oxygenated molecules is not perfectly predicted because thermodynamic models and equations of state used in process design traditionally come from oil and gas engineering, and thus fail for these compounds. Indeed, strong association interactions like hydrogen bonding or dimerization are not taken into account in oil and gas engineering models. Thus, it is important to have accurate predictive models with limited parameters to describe their behaviour, since it is of a great importance for the chemical industry especially for the design of new production processes from lignocellulosic material [4]. For this purpose, the MEMOBIOL project (Molecular Scale Modeling for Lignocellulosic Biorefineries financed by the French National Research Agency (ANR-09CP2D-10-04)) has been done in order to evaluate different predictive tools for calculating the thermodynamic phase equilibria and properties required by the chemical industry. The CTP was one of the academic partners involved in this project, in which new Vapour-Liquid and Liquid-Liquid equilibrium experimental data of different binary and ternary systems containing high added-value oxygenated molecules and different solvents have been determined ([5-6])

In this paper, we focused on furan as a derived molecule obtained from the pyrolysis of the lignocellulosic biomass. It intervenes in the acid-catalyzed hydrolysis of xylan-type hemicelluloses [7]. One application is the production of the Tetrahydrofuran (THF) solvent, widely used in chemical and technological processes [8]. It can be also used as a precursor for the synthesis of pharmaceutical molecules ([9]). Apparent Henry's law constants of furan in different alkane and alcohol solvents have been measured using a gas inert stripping method. Activity coefficients at infinite dilution have been deduced. These properties are useful to 
evaluate the deviation from ideality and then to determine the most suitable solvent of extraction.

\section{EXPERIMENTAL SECTION}

\subsection{Chemicals}

Chemicals used in this study are presented in Table 1.

\subsection{Equipment}

Apparent Henry's Law Constant and Infinite Dilution Activity Coefficient determination was conducted with the gas stripping method using a specially designed apparatus using dilutor and saturator cell. The experimental procedure is fully described by Richon et al. [10-11] and Krummen et al. [12]. Both cells are inside a liquid bath regulated within $0.01 \mathrm{~K}$. A platinum probe, in contact with the liquid phase of the "dilutor cell" is connected to an electronic display. Temperature accuracy after probe calibration is below $0.1 \mathrm{~K}$. The composition of the gas leaving the cell is periodically sampled and analysed using gas chromatograph (PERICHROM model PR2100, France) equipped with a flame ionization detector connected to a data acquisition system (Winilab III). The analytical column was: PORAPAK Q 80/100 MESH (1/8" Silcosteel tube, length: 1.2 m, ID: 2 mm, Restek, France).

The flow meter (Analyt-MTC, Messtechnik GmbH \& co, model 358) was calibrated using bubble flow meter with the carrier gas (Helium). The apparent Henry's law coefficient, H, of solute $i$ can be calculated with Equation 1, obtained from mass balance on the dilutor cell.

$$
H_{i}=-\frac{1}{t} \ln \left(\frac{S_{i}}{\left(S_{i}\right)_{t=0}}\right) \frac{R T N}{1-\frac{P_{\text {solv }}^{\text {sat }}}{P}}+\frac{V_{G}}{t} \ln \left(\frac{S_{i}}{\left(S_{i}\right)_{t=0}}\right)
$$

Parameters of Equation 1 are given in Table 2. Vapour pressure (in Pa) has been calculated with the DIPPR equation $n^{\circ} 101$ (Equation 2 ) with the corresponding parameters (Table 3 ).

$$
\ln \left(P^{s a t}\right)=A+\frac{B}{T}+C \ln (T)+D T^{E}
$$


The maximal relative uncertainty of the Apparent Henry's law coefficient $\mathrm{U}\left(H_{i}, \mathrm{k}=2\right) / H_{i}$ is estimated to be $4.7 \%$. It takes into account the uncertainties related to the flow, solute peak area determination, temperature, pressure and number of moles of the solvent. Equation 3 reminds the mathematical expression used to calculate the uncertainties. Uncertainties on repeatability $\left(\mathrm{u}_{\mathrm{rep}}\right)$ are calculated considering the measurements done with at least three different flow values and are about $2 \%$. Equation 4 details the method for the determination of the uncertainty on calculation $\left(\mathrm{u}_{\mathrm{cal}}\right)$.

$$
u\left(H_{i}\right)=\sqrt{\left(u_{r e p}\left(H_{i}\right)^{2}+u_{c a l}\left(H_{i}\right)^{2}\right)}
$$

$u_{\text {cal }}\left(H_{i}\right)$

$$
=\sqrt{\left\{\begin{array}{c}
\left(\frac{\partial H_{i}}{\partial \alpha}\right)_{P, D, T, N, V_{G}}^{2} u(\alpha)^{2}+\left(\frac{\partial H_{i}}{\partial P}\right)_{\alpha, D, T, N, V_{G}}^{2} u(P)^{2}+\left(\frac{\partial H_{i}}{\partial D}\right)_{\alpha, P, T, N, V_{G}}^{2} u(D)^{2}+\left(\frac{\partial H_{i}}{\partial T}\right)_{\alpha, D, P, N, V_{G}}^{2} u(T)^{2} \\
+\left(\frac{\partial H_{i}}{\partial N}\right)_{\alpha, D, T, P, V_{G}}^{2} u(N)^{2}+\left(\frac{\partial H_{i}}{\partial V_{G}}\right)_{\alpha, D, T, N, P}^{2} u\left(V_{G}\right)^{2}
\end{array}\right\}}
$$

with $\alpha$ the slope of the curve $-\frac{1}{t} \ln \left(\frac{S_{i}}{\left(S_{i}\right)_{t=0}}\right)$.

\section{EXPERIMENTAL RESULTS AND DISCUSSION}

\subsection{Apparent Henry's law constant and activity coefficient at infinite dilution}

Apparent Henry's law constant is directly determined using the gas stripping method as previously described. The symmetric convention links the apparent Henry's law constant with the activity coefficients at infinite dilution (Equation 5), assuming that the Poynting factor and the fugacity coefficient have a value of approximately unity [13].

$$
\gamma_{i}^{\infty}=\frac{H_{i}\left(T, P_{\text {solv }}^{\text {sat }}\right)}{P_{i}^{\text {sat }}}
$$

Experimental data of measurements in n-alkanes are tabulated in Table 4 and the ones in alcohols in Table 5.

To study the temperature dependence, the logarithm of the activity coefficient at infinite dilution of furan in some solvents is drawn as a function of inverse temperature (Figure 1). 
From Tables 4 and 5 and Figure 1, the following observations can be made:

(a) the limiting activity coefficients values are a decreasing function with the temperature, except for ethanol (close to a monotonic behaviour);

(b) a nonlinear behaviour of $\ln \left(\gamma_{i}^{\infty}\right)$ versus $1 / T$ is observed for $n$-pentane and $n$-hexane;

(c) for both alcohols and alkanes (except $n$-pentane), the $\gamma_{i}^{\infty}$ values decrease with increasing number of carbon atoms. A hypothesis for $n$-pentane behaviour would the difference of volatility between all hydrocarbons and its boiling temperature close to the one of furan;

(d) limiting activity coefficients of furan in alkanes are closer to one (value of ideal mixture) than in alcohols: alkanes would be better solvents for furan than alcohols.

(e) $n$-pentane has the lowest activity coefficient value at infinite dilution.

From these data, $n$-pentane seems to be the better solvent to extract furan at temperatures below $300 \mathrm{~K}$.

\subsection{Chemical engineering criteria}

In chemical engineering, different criteria, calculated with activity coefficient at infinite dilution, can help to select a solvent [13]. One may mention distribution coefficient or selectivity. In our study, we can calculate the solvating power $\left(S_{p}\right)$. It is the criterion representing the ability of a solvent to form strong secondary bonds with solute molecules. It can be calculated with Equation 5 .

$$
S_{p}=\frac{1}{\gamma_{A, \text { solv }}^{\infty}} \frac{M_{\text {solv }}}{M_{A}}
$$

where $\mathrm{M}_{\text {solv }}$ and $\mathrm{M}_{\mathrm{A}}$ are the molar mass of the solvent and the solute respectively.

Solvating power values of the different solvents presented in this paper and toluene are drawn on Figure 2 at 298K. Based on Figure 2 and previous conclusions, toluene, and to a lesser extent $n$-pentane, seem to be appropriate solvents for furan extraction.

\subsection{Phase equilibria data}

Vapour-Liquid and Vapour-Vapour-Liquid Equilibrium data have been previously measured for some furan-solvent binary systems (toluene, $n$-hexane, ethanol and $n$-octanol). It has been shown that the binary toluene-furan system presents a Raoult's law behaviour [5-6]. This 
ideal behaviour has been confirmed with excess enthalpy [14] and excess volume [5] measurements. From these data, two conclusions can be drawn: toluene seems to be the better solvent to extract furan and apparent Henry's law constant measurements appears to be an appropriate setup in terms of time consumption, costs and ease of use.

However, only apparent Henry's law constants do not provide any information about the probability to have an azeotrope. Since no data are available for the $n$-pentane-furan system in the open literature, has been predicted at atmospheric pressure using the original UNIFAC model [15]. As shown on Figure 3, this system has an azeotrope.

Original UNIFAC is also used to predict phase diagram of furan $+n$-hexane and furan+toluene binary systems at atmospheric pressure. This model seems to predict correctly both phase diagrams (Figure 3). Therefore, even if the limiting activity coefficient analysis presents $n$ pentane as a potential solvent for furan extraction, from a process point of view, it is not suitable since it would be difficult to separate the solute and the solvent using distillation column.

\section{CONCLUSION}

In this study, apparent Henry's law constant of furan in eight normal alkane $\left(\mathrm{C}_{5}\right.$ to $\mathrm{C}_{10}, \mathrm{C}_{12}$ and $\mathrm{C}_{16}$ ) and eight (primary and secondary) alcohol solvents have been measured using the inert gas stripping method. To the best of our knowledge, no apparent Henry's law constant data are available for furan in the open literature. From these data, activity coefficients at infinite dilution have been calculated. If referring to Henry's law constants, $n$-pentane seems to be an appropriate solvent for furan extraction. However, VLE data are necessary to confirm or not this assumption. Indeed, VLE prediction with the UNIFAC models shows that the npentane-furan binary system presents an azeotrope. Therefore, more thermophysical properties (such as VLE, partition coefficient of the solute/solvent system, density and surface tension) are needed to choose the adequate solvent for furan extraction.

\section{ACKNOWLEDGMENTS}

The ANR through the project Memobiol (ANR-09-CP2D-10-04 MEMOBIOL) is gratefully acknowledged for the financial support. 


\section{REFERENCES}

[1] International Energy Outlook 2016 - With Projections to 2040. 2016, U.S Energy Information Administration.

[2] Lange, J.P., et al., Furfural A Promising Platform for Lignocellulosic Biofuels. Chemsuschem, 2012. 5(1): p. 150-166.

[3] Harmsen, P.F.H., et al., Literature Review of Physical and Chemical Pretreatment Processes for Lignocellulosic Biomass. ECN-E--10-013, September 2010.

[4] Lugo, R., et al., Molecular-Based Predictive Models Applied to High Value OxygenBearing Molecules and their Mixtures, XIX International Conference on Chemical Thermodynamics. June 24-28, 2013: Russia (Moscow).

[5] Nala, M., et al., Vapour-Liquid Equilibrium (VLE) for the Systems Furan plus n-Hexane and Furan plus Toluene. Measurements, Data Treatment and Modeling Using Molecular Models. Fluid Phase Equilibria, 2013. 337: p. 234-245.

[6] Auger, E., et al., Equilibrium Data and GC-PC-SAFT Predictions for Furanic Extraction. Fluid Phase Equilibria, 2016. 430: p. 57-66.

[7] Besson, M., P. Gallezot, and C. Pinel, Conversion of Biomass into Chemicals over Metal Catalysts. Chemical Reviews, 2014. 114(3): p. 1827-1870.

[8] Alkhaldi, K., A.S. Al-Jimaz, and M.S. AlTuwaim, Densities, Ultrasonic Speeds and Refractive Indices of Phenetole with N-Methyl-2-Pyrrolidone, N,N-Dimethylformamide and Tetrahydrofuran Binary Mixtures at Different Temperatures. Journal of Chemical Thermodynamics, 2016. 103: p. 249-256.

[9] Joule, J.A., K. Mills, and G.F. Smith, Heterocyclic Chemistry. 1995, Chapman \& Hall, London.

[10] Richon, D., P. Antoine, and H. Renon, Infinite Dilution Activity-Coefficients of Linear and Branched Alkanes from $C_{1}$ to $C_{9}$ in N-Hexadecane by Inert-Gas Stripping. Industrial \& Engineering Chemistry Process Design and Development, 1980. 19(1): p. 144-147.

[11] Richon, D. and H. Renon, Infinite Dilution Henry Constants of Light-Hydrocarbons in Normal-Hexadecane, Normal-Octadecane, and 2,2,4,4,6,8,8-Heptamethylnonane by InertGas Stripping. Journal of Chemical and Engineering Data, 1980. 25(1): p. 59-60.

[12] Krummen, M., D. Gruber, and J. Gmehling, Measurement of Activity Coefficients at Infinite Dilution in Solvent Mixtures Using the Dilutor Technique. Industrial \& Engineering Chemistry Research, 2000. 39(6): p. 2114-2123. 
[13] Scilipoti, J.A., et al., Selection of Solvents with A-UNIFAC Applied to Detoxification of Aqueous Solutions. Industrial \& Engineering Chemistry Research, 2014. 53(44): p. 1705117058.

[14] El Ahmar, E., et al. Experimental and Predicted Excess Molar Volumes and Enthalpies of Binary Systems Containing Furan. ICCT 2012, August 5-10 (2012). Búzios RJ (Brazil).

[15] Fredenslund, A., R.L. Jones, and J.M. Prausnitz, Group-Contribution Estimation of Activity-Coefficients in Nonideal Liquid-Mixtures. AIChE Journal, 1975. 21(6): p. 1086-1099. 